\title{
Varejo de luxo: A influência dos trajes usados por clientes na qualidade do atendimento
}

\author{
Fabiana Pacheco Franco ${ }^{1}$ \\ Rejane Alexandrina Domingues Pereira do Prado ${ }^{2}$ \\ Kelly Aparecida Silva ${ }^{3}$
}

\section{Resumo}

Um atendimento personalizado é um diferencial para a geração de valor e a fidelização do cliente, mas muitas vezes o preconceito frente a vestimenta do comprador pode ser um empecilho para que isso aconteça. O presente estudo é do tipo descritivo com abordagem qualitativa e investiga o preconceito no atendimento oferecido por lojas de varejo de luxo em função do traje usado pelos clientes. A coleta de dados consistiu na ação de dois clientes espiões, ora bem vestidos, ora malvestidos, que visitaram e relataram o atendimento de seis lojas luxuosas em uma cidade localizada no interior de Minas Gerais. Os resultados inferem que o preconceito é maior em relação ao atendimento às mulheres. Notou-se que quando a cliente espiã estava malvestida os vendedores atendiam por obrigação e sem demonstração de simpatia ou vontade de vender os produtos. Quando bem vestida havia preocupação dos vendedores em todos os aspectos, procurando deixa-la à vontade e mostrando todos os produtos possíveis. Com o cliente espião do gênero masculino observou-se a preocupação quanto a forma de pagamento e demonstração de roupas da promoção, quando malvestido. Quando bem vestido, não se preocuparam com formas de pagamento e mostravam vários produtos sem distinção de preços.

Palavras-Chave: Cliente espião, luxo, preconceito, vestuário

\section{Lux retail: The influence of costumes worn by customers on the quality of costumer service}

\begin{abstract}
A personalized service is a differential for the generation of value and customer loyalty, but often the prejudice against the buyer's clothing can be a hindrance to that. The present study is descriptive with a qualitative approach and investigates the prejudice in the service offered by luxury retail stores due to the suit worn by clients. The collection of data consisted of the action of two well-dressed, sometimes poorly dressed, spy shoppers who visited and reported the service of six luxury stores in a city located in the interior of Minas Gerais. The results infer that the prejudice is greater in relation to the care given to women. It was noted that when the spy client was undressed the sellers attended by obligation and without demonstration of sympathy or willingness to sell the products. When dressed well there was concern of the sellers in all aspects, trying to leave it at ease and showing all possible products. With the spy client of the masculine gender was observed the preoccupation as to
\end{abstract}

1 Graduada em Administração pela Universidade Federal de Uberlândia. fabiana_fpf@yahoo.com.br

${ }^{2}$ Doutora em Administração na Universidade Nove de Julho (UNINOVE), Professora de Marketing na Universidade Federal de Uberlândia (UFU). realexandrina@ yahoo.com.br

3 Mestranda em Ciências Contábeis (UFU), Especialista em Engenharia e Inovação (ESTÀCIO). Kelly_asilva@yahoo.com.br 
the form of payment and demonstration of clothes of the promotion, when undressed. When well dressed, they did not care about payment methods and showed several products without distinction of prices.

Key-words: Customer spy, lux, prejudice, clothing

\section{INTRODUÇÃO}

Impulsionada pela crescente exigência dos clientes, a qualidade dos serviços tem se tornado um motivo de preocupação para as empresas. Um atendimento personalizado é considerado um diferencial no que tange a fidelização de cliente sendo, portanto, peça fundamental para a potencialização da vantagem competitiva em relação aos demais concorrentes (TEIXEIRA E FREITAS, 2004).

O presente milênio contempla todas as estratégias voltadas para a qualidade do atendimento aos clientes, a globalização do mercado exige tecnologia e descarta a mão-deobra despreparada e o atendimento personalizado tornou-se um dever das empresas. Deste modo, é preciso promover mudanças, pois "atender é basicamente satisfazer às necessidades imediatas ou os desejos e expectativas dos clientes". Logo, as causas de um atendimento inferior ao esperado pelo cliente por falta de qualidade, quase sempre se encontram no âmbito operacional. Por isso, as empresas devem transformar o ambiente de atendimento num posto de observações das reações dos clientes, colhendo dados e transformando-os em informações que solidifiquem estratégias (GREIS; SILVA, 2008).

A identificação e aplicação adequada da qualidade e da geração de valor de bens e serviços contribuem para a estratégia de conquista de novos clientes. Em outras palavras, a qualidade está entre os atributos listados nos objetivos da empresa e é considerada alicerce fundamental para a conquista de uma posição mais forte e competitiva, uma vez que deve ser percebida e definida pelo cliente (XAVIER, 2011).

Para João Abdalla, consultor do SEBRAE - Serviço Brasileiro de Apoio às Micro e Pequenas Empresas, é basal compreender que a essência da qualidade no atendimento ao cliente não se resume a tratá-lo bem, mas em superar suas expectativas, apresentando um produto ou serviço com valor superior ao que o cliente procurava. Essa filosofia, que prioriza as necessidades e interesses da clientela - e não os da empresa - promove um aumento dos negócios em função da fidelização dos compradores (GREIS; SILVA, 2008). 
Um dos fatores que prejudicam o atendimento é o preconceito quanto a vestimenta do cliente. Segundo Allport (1954), o preconceito é o resultado das frustações das pessoas, que, em determinadas circunstâncias, podem se transformar em raiva e hostilidade. As pessoas que se sentem exploradas e oprimidas frequentemente não podem manifestar sua raiva contra um alvo identificável ou adequado. Assim, deslocam sua hostilidade para aqueles que estão ainda mais baixo na escala social, resultando em preconceito e discriminação.

A discriminação é praticada a todo o momento, em todo o mundo, constituindo uma prática universal. Em lugares onde existem diferenças ocorre a discriminação e várias pessoas são prejudicadas por algum motivo, seja por pertencerem a determinado grupo, por sua cor, orientação sexual, religião, ou qualquer outro motivo que seja algo considerado diferente pela sociedade (SOARES, 2000).

Neste contexto, o presente estudo é motivado pela compreensão do pré-julgamento acerca da formação de estereótipos na compra de artigos de luxo em detrimento de sua aparência e busca responder a seguinte questão: A vestimenta interfere na forma de atendimento aos clientes em lojas de confecções luxuosas? Admite-se como objetivo geral a identificação de preconceito no atendimento das lojas de confecções de luxo em função dos trajes usados pelos clientes em uma cidade localizada no pontal do Triângulo Mineiro. Para alcance do objetivo, dois clientes-espiões visitaram seis lojas luxuosas. Este trabalho encontra-se estruturado em cinco seções. A primeira constitui-se da introdução, a segunda compreende o referencial teórico, seguida dos procedimentos metodológicos, discussão dos resultados e considerações finais, respectivamente.

\section{REVISÃO TEÓRICA}

\subsection{Lojas de Varejo}

Segundo Kotler e Keller (2006, p.500) “o varejo inclui todas as atividades relativas à venda de produtos ou serviços diretamente ao consumidor final, para uso pessoal e não comercial". Um varejista ou uma loja de varejo é qualquer empreendimento comercial cujo faturamento provenha principalmente da venda de pequenos lotes no varejo. Qualquer organização que venda para os consumidores finais seja fabricante, distribuidor/atacadista ou varejista está executando a atividade varejo.

Parente (2000) classificações o varejo em três grandes grupos: 
a) O primeiro grupo: abrange a classificação de acordo com a propriedade, onde o varejo é dividido em lojas independentes que possuem apenas uma loja, são as empresas basicamente familiares; as redes possuem mais de uma loja sob a mesma direção, como exemplo C\&A e RENNER; as franquias consistem em um sistema contínuo e integrado de relacionamento onde o franqueado conduz o negócio de acordo com os padrões definidos pelo franqueador; os departamentos alugados são departamentos existentes dentro de uma loja de varejo, mas operados por outra empresa.

b) $\mathrm{O}$ segundo grupo é constituído pelas instituições com lojas, classificadas em varejo alimentício, que é todo e qualquer varejo que vende alimentos, como bares, mercearias, padarias, minimercados, lojas de conveniência, supermercados e hipermercados. Já o varejo não alimentício vende produtos que não são classificados como alimentos e/ou bebidas e ddivide-se em lojas especializadas, lojas de departamentos, mini lojas de departamentos ou magazines. Neste grupo existe também o varejo de serviços, caracterizado pela prestação de serviços, como salão de beleza, clínica médica, academia de ginástica e outros.

c) E, por fim, o terceiro grupo é constituído por instituições sem loja, onde tem-se as vendas diretas, que possuem um sistema de venda ao consumidor que envolve explicações e demonstrações de produtos e serviços. Já a máquina de vendas é caracterizada pela venda de produtos através de máquinas, executada diretamente pelo consumidor, enquanto o varejo virtual é um sistema de vendas que conta com uma localização cibernética para a loja, tendo como ambiente a Internet.

As lojas de varejo têm suas próprias imagens que servem para influenciar a qualidade percebida dos produtos de que dispõem e as decisões dos consumidores sobre onde comprar. Essas imagens se originam de seu projeto e ambiente físico, de suas estratégias de preços e do mix de produtos. Examinando os efeitos de determinados fatores ambientais da loja sobre as inferências da qualidade descobriu-se que as percepções do consumidor eram influenciadas mais fortemente pelos fatores ambientais (como o número, o tipo e o comportamento dos outros clientes dentro da loja e do pessoal de vendas) do que pela característica do desenho da loja (SCHIFFMAN; KANUK, 2009). O presente estudo focará o atendimento no varejo com loja, sendo estas, lojas de confecções de roupas consideradas como varejo de luxo, o que será discutido na próxima seção.

\subsubsection{Varejo de Luxo}


O varejo é definido como o conjunto de todas as atividades que fazem parte do processo de venda de produtos e serviços com o objetivo de atender à necessidade pessoal do consumidor final (PARENTE, 2000). O luxo pode ser definido como tudo o que supera a necessidade e vale ainda ressaltar que o seu conceito se molda de acordo com as mudanças da sociedade (CASTARÈDE, 2005).

O consumo de produtos de luxo vem crescendo cada dia mais independente da situação em que o mercado econômico se encontra. Em meados do século 17 e 18, os produtos de luxo eram destinados somente à burguesia, sem se estender para os demais grupos sociais. Atualmente, o luxo está presente em cada categoria de produto ou serviço existente no mercado (D'ANGELO, 2006).

Segundo Viera e Silva (2011), existe uma segmentação, onde para cada classe social existe um tipo de consumidor disposto a consumir a diversidade de produtos ou serviços de luxo, conforme figura 1.

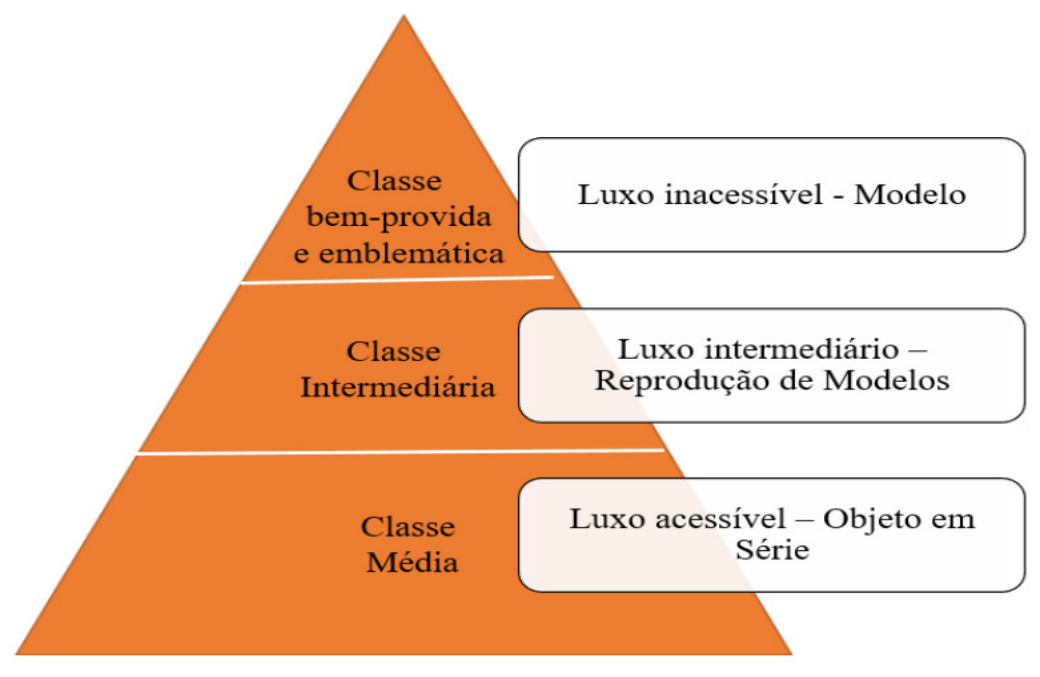

Figura 1 - Hierarquia dos objetos de luxo Fonte: VIEIRA E DEL-VECHIO, 2011, p.86.

A classe melhor provida economicamente sempre consumiu o luxo, realiza compra de objetos tradicionais, mais caros e mais raros. Já a classe intermediária se contenta com objetos que foram fabricados em pequena série por criadores da moda, enquanto a classe média é a mais consumista, principalmente de objetos em série, preocupando-se em adquirir um objeto como se fosse um patrimônio cultural das marcas (VIEIRA; DEL-VECHIO, 2011).

Muito embora o luxo nunca sofra com a crise, pelo fato de que sempre terá consumidores dispostos a pagar por altos preços, consecutivamente objetiva o lucro 
obedecendo à lógica soberana de qualquer mercado, onde a empresa busca por bons resultados financeiros. Com isso, onde há pessoas consumistas de produtos de altos valores há garantia de lucro da loja, com a percepção de bons resultados, o que tem levado muitas marcas mundiais a investir no Brasil (D’ANGELO, 2006).

O luxo tornou-se parte da economia para muitas nações, constituindo um setor que movimenta o volume de negócios e que cresce constantemente, aumentando a geração de trabalho e renda. O luxo é tudo que é raro ou incomum e sofre variações com o passar do tempo. É visto com um reflexo da personalidade da sociedade em épocas diferentes. Desde a década de 80, quando houve o desenvolvimento internacional dos produtos de luxo, surgiram, junto com a globalização, grupos de consumidores de várias marcas (VIERA; SILVA, 2011).

As lojas físicas são importantes recursos estratégicos para a gestão dos negócios dos produtos de luxo, pois é nesse espaço que são realizadas as compras e que os clientes vivem experiências únicas adquirindo produtos desejáveis de marcas famosas. É nesse ambiente também que ocorre o contato imediato do cliente com o produto, onde são conhecidas as características, o processo de fabricação e a história da marca, e como resultado tem-se um cliente aperfeiçoado, que entende sobre o mercado de luxo (PIANARO, 2007).

Os varejistas encontram a oferta de produtos exclusivos e diferenciados para diminuir a concorrência. A estratégia do varejo de produtos de luxo se baseia na diferenciação, o que colabora para evitar uma confusão entre os consumidores sobre as várias lojas de luxo (SCHMID, 2003; ROUX, 2005)

Uma das questões relevantes no varejo de luxo é a qualidade no atendimento prestado. De acordo com Faria (2012), é no varejo que ocorre a união de fatores racionais e emocionais que levam o consumidor à decisão final de compra, pois há uma relação entre o vendedor, o consumidor e o ambiente de serviço. Este assunto será discutido na próxima seção.

\subsection{Qualidade no atendimento}

O termo qualidade significa satisfazer o consumidor atendendo todas as suas necessidades. Martins (1998) afirma que até a década de 60 o mercado exigia preço e a empresa tinha que ser eficiente para competir e ganhar novos mercados. Na década de 70 , além do preço, as exigências da população voltaram-se para a qualidade.

O cliente se tornava, cada vez mais, uma pessoa mais exigente, que além de um produto de qualidade, queria algo diferente, buscando também a inovação. Ele é único e quer 
ser tratado como tal. Para o consumidor, a inovação não está apenas nos produtos, mas nos funcionários das empresas, no bom atendimento que será prestado a fim de satisfazer a necessidade do cliente e suprir suas expectativas (MARTINS, 1998).

Para tornar um atendimento mais eficaz e satisfatório para o consumidor, a solução de problemas ou falhas no desempenho dos serviços pode iniciar-se, principalmente, quando a empresa começa a buscar conhecimentos, informações sobre seus clientes e consumidores, suas opiniões, percepções, dentre outros. Essas informações não podem ser prenunciadas, mas devem ser investigadas, pesquisadas diretamente com os clientes e decodificadas para aplicação efetiva de melhorias no desempenho dos serviços (MATOS, 2000).

A velocidade de atendimento demonstra a prontidão da organização e de seus atendentes na prestação do serviço. Existem duas dimensões de tempo: a real e a percebida. Enquanto a primeira é caracterizada pelo tempo físico de espera em minutos, horas ou dias, que pode ser reduzido com investimentos que promovam modificações no processo ou adição de capacidade, a percebida engloba a percepção dos clientes sobre o tempo que precisam esperar no atendimento, cuja adequação requer introdução de artifícios que os distraiam enquanto esperam, como, por exemplo, músicas, revistas, vídeos, entre outros (MATOS, 2000). A qualidade percebida pelo cliente pode ser obtida a partir de uma comparação entre a sua expectativa e a percepção, como observado na figura 2.

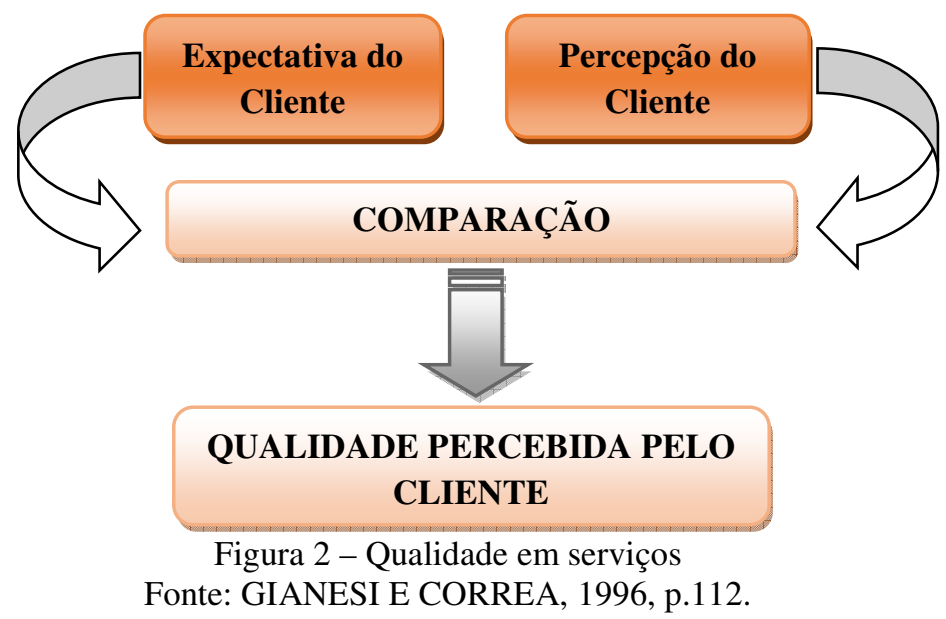

\section{Figura 1 - Qualidade em Serviços}

As expectativas dos clientes que concebem as percepções em descrição ao produto e aos serviços são planeadas pelas informações sobre a empresa, sobre as experiências de terceiros e principalmente pelas suas necessidades (ROCHA; LIMA, 2009). A qualidade no atendimento será responsável pela satisfação do cliente, conforme discutido na próxima seção. 


\subsection{Satisfação do Cliente}

O cliente sempre será a pessoa mais importante da empresa, pois é ele quem leva a ela suas necessidades e é a razão de sua existência. O comprador não está mais em busca de opções, ele sabe exatamente o que quer ou, pelo menos, sabe o que não quer. Atendimento de baixa qualidade, displicência e desinteresse são atitudes que desencantam o cliente que por sua vez desiste da relação de compra e muitas vezes divulga suas insatisfações com demais compradores em potencial (MARTINS, 1998).

Da mesma forma, os consumidores procuram informações sobre produtos e categorias de produtos por meio do "boca a boca" (com amigos, família e outras pessoas cujas opiniões por eles são prezadas), de vendedores e da mídia em geral. Despendem mais tempo pensando sobre suas escolhas e buscam mais informações sobre as alternativas do produto quando associam um alto grau de risco à compra. Essa estratégia é direta e lógica sobre o produto e a categoria do produto, mais previsíveis são as prováveis consequências e, assim, menor o risco percebido (SCHIFFMAN; KANUK, 2009).

Os clientes podem ser subdivididos em três categorias, de acordo com suas exigências de qualidade. A primeira é constituída por aqueles que veem o desempenho ou a singularidade de um produto como componente especial de valor. Eles estão interessados no melhor produto e em suas características, que vão gerar os resultados desejados, portanto, o produto estabelece o valor. Já na segunda categoria, os clientes são aqueles que dão muito valor ao atendimento e aconselhamento personalizados. Eles estão mais preocupados com seus requisitos individuais e suas necessidades não podem ser satisfeitas por produtos padronizados ou preços justos. Enfim, a terceira categoria, envolve aqueles clientes que buscam o menor custo total, combinando preço e confiabilidade, além de um atendimento rápido e sem chateações (MARTINS, 1998).

A satisfação pode ser definida como sendo a resposta de plenitude do cliente, ou seja, o julgamento que um produto ou serviço tem como característica, devido ao fato de ter provido, ou estar provendo um nível agradável de plenitude relacionada ao consumo, pode incluir níveis um pouco abaixo ou que superem o nível esperado (MILAN; TREZ, 2005).

A satisfação do cliente é a percepção individual do desempenho do produto ou serviço em relação a suas expectativas. O conceito de satisfação do cliente decorre em função de suas 
expectativas. Um cliente cuja experiência fique abaixo das expectativas, consequentemente, ficará insatisfeito. Os frequentadores cujas experiências atendem às expectativas ficarão satisfeitos e os clientes cujas expectativas são excedidas ficarão muito satisfeitos ou encantados (SCHIFFMAN; KANUK, 2009).

Em resumo, a satisfação pode ser definida como o grau no qual o cliente acredita que as suas expectativas serão supridas ou excedidas por meio dos benefícios recebidos, ou também como o sentimento do consumidor no que se refere aos resultados provenientes do consumo em relação a um padrão de prazer ou desprazer. A empresa que oferece bom atendimento terá maior facilidade em trabalhar a atração, retenção e manutenção de clientes, o que será discutido na próxima seção.

\subsection{Atração, Retenção e Manutenção de Clientes}

A empresa que tem como objetivo o crescimento do lucro e das vendas deve investir em tempo e recursos para a busca de novos clientes. Para alcançar esse objetivo, a empresa usa diversos meios de comunicação como: peças publicitárias, mala direta, contato telefônico com possíveis clientes futuros. Também é viável o encaminhamento de seus funcionários para participação em feiras setoriais, onde é possível encontrar novas indicações. Todo esse processo traz como resultado uma lista de possíveis clientes, que são pessoas ou organizações que possivelmente terão interesse em adquirir o produto ou serviço de determinada empresa, sem intenção concreta de comprá-lo [...] (KOTLER; KELLER, 2006).

Com o crescente nível de competitividade no mercado, pode-se inferir que a retenção de clientes é fundamental. Assim, o grande desafio passa a ser o de reconhecer os clientes, mostrando-lhes o quanto a empresa os estima por ser selecionada. No entanto, este fato extrapola a preocupação com a simples satisfação do cliente por ser um novo modo de pensar a respeito sobre o que gera lucros e a forma de fazer negócios (MILAN, 2006).

É mais difícil agradar os clientes, já que as pessoas se tornaram mais inteligentes e observadoras em relação a preços e exigentes quanto à qualidade e atendimento. Tornar um cliente fiel é um grande desafio, visto que a concorrência em todas as aéreas é elevada (KOTLER; KELLER, 2006).

Nesse contexto, o papel dos funcionários revela-se importante, pois as evidências indicam que funcionários satisfeitos aumentam a satisfação e a lealdade dos clientes. Isso ocorre porque a retenção ou a perda de clientes nas empresas de serviços depende muito da 
maneira com que esses clientes são tratados. Como a tendência de funcionários satisfeitos é a permanência de mais tempo no emprego, existe uma maior probabilidade de que os clientes encontrem rostos familiares e recebam o atendimento que já conhecem. Aspectos como esse são responsáveis pela construção da satisfação e da lealdade dos clientes (KOTLER; KELLER, 2006).

Algumas regras básicas fortalecem a manutenção de um comprador na empresa, como é o caso do desenvolvimento da comunicação com o cliente, estabelecimento de um contato periódico para ouvir críticas e elogios, desenvolvimento de pesquisas e análise dos resultados para a criação de novas estratégias para a empresa e, por fim, recompensá-lo pela dedicação de seu tempo para colaborar com a empresa (RAPP; COLLINS, 1996).

Para a retenção de clientes existem duas maneiras. Uma é erguer barreiras para impedir a mudança para outro fornecedor. Quando há um alto custo de capital, altos custos relacionados à pesquisa de novos fornecedores e não há desconto para clientes fiéis o consumidor fica sujeito a uma nova mudança. Porém, o melhor método é a satisfação sentida pelo cliente ao final do serviço. Se ele está bem com aquela empresa ou fornecedor ele não pensará na hipótese de mudar para outra [...] (KOTLER; KELLER, 2006).

No que tange a retenção dos clientes, vale ressaltar que novos clientes podem custar até cinco vezes mais do que satisfazer e reter os já existentes. Afinal, não é fácil induzir clientes satisfeitos a deixar de contratar seus fornecedores atuais. As empresas perdem em média dez por cento de seus clientes a cada ano e conforme o setor, uma redução de cinco por cento no índice de perda de clientes pode aumentar os lucros de 25 a 85 por cento. A taxa de lucro por cliente tende a aumentar ao longo do tempo de permanência do cliente retido (SHPAIRO; SVIOKLA, 1995).

A satisfação do cliente vem ganhando grande importância nas empresas, como uma forma de retenção dos clientes. Se uma empresa estiver à venda, o comprador não pagará apenas pelas instalações, equipamentos e pela marca, mas sim pelos clientes já fiéis ali. Logo, se a empresa continuar com a mesma forma de tratar os clientes, eles não iriam mudar pelo fato se ser um novo proprietário (KOTLER; KELLER, 2006).

De acordo com Milan (2006), o custo de retenção de um cliente atual é menor que um custo de atração de um novo cliente. Embora com controvérsias, algumas estimativas ilustram a relação entre os custos de aquisição e os custos de manutenção de clientes. Kotler e Keller (2006), por exemplo, defendem que os custos de aquisição podem chegar até cinco vezes mais 
em relação aos custos de manutenção. Para o consumidor, vários itens influência no momento da compra, o ambiente de serviço é um deles, que será discutido na próxima seção.

\subsection{Ambiente de Serviço no Varejo}

O ambiente de serviço é um importante fator na experiência de trabalho e no aumento ou diminuição de satisfação dos clientes [...]. Os serviços são considerados intangíveis, por isso em muitos casos, os consumidores avaliam a qualidade de uma empresa na sua imagem, no ambiente em que é oferecido um serviço, e com isso as empresas trabalham seu conceito, voltada para a satisfação do consumidor (LOVELOCK; WIRTZ; HEMZO, 2011).

Parente (2000) considera que o ambiente físico é capaz de definir a loja de acordo com o sentimento físico que o varejista deseja desenvolver no consumidor. Quando ele se dirige até a loja e os varejistas utilizam recursos que sejam capazes de influenciar outros sentidos dos clientes, como visão e olfato.

Alguns cenários de serviços são funcionais. Empresas que querem passar a imagem de baixo custo localizam-se em regiões estratégicas, onde as instalações são simples, os uniformes dos funcionários são baratos e comuns, mas nem sempre essa estratégia funciona. $\mathrm{Na}$ maioria das vezes o cliente tem certa criatividade para dominar o espaço, e o utiliza de diversas formas (LOVELOCK; WIRTZ; HEMZO, 2011).

A apresentação externa da loja é o que provoca o primeiro impacto no cliente, e quando o cliente entra na loja, as impressões se aprofundam, pois, tem o ambiente externo para análise. Quando o consumidor visita a loja, a atmosfera se compreende como um fator psicológico que é estimulado pelo varejista (PARENTE, 2009). O aspecto da loja, é determinante, para a efetivação da compra, articulando as variáveis controláveis. Para a criação de um espaço comercial funcional, é preciso a combinação de arquitetura, engenharia, psicologia e marketing (SANTOS E GOMES, 2009).

O layout e a funcionalidade são dois fatores relevantes para que haja um bom ambiente de serviço e se refere ao tamanho, ao formato e à maneira como são colocados os móveis e equipamentos, de acordo com o serviço prestado. Já a funcionalidade é a capacidade desses itens ao facilitar o desempenho de transações de serviço. Esses dois fatores criam um cenário de serviço visual e funcional para que a entrega e o consumo do produto ou serviço ocorram, influenciando no atendimento ao cliente, como o estacionamento, por exemplo. Se o 
consumidor chega a determinado local sem vaga ou com estacionamento irregular, ele pode ir em busca de uma loja que tenha um estacionamento adequado. Até mesmo dentro da loja, se existem produtos espalhados de forma exagerada, isso pode interferir na circulação do cliente, sufocando-o e provocando a desistência da compra (LOVELOCK; WIRTZ; HEMZO, 2011).

As pessoas que desempenham atividades em um ambiente de serviço também devem estar capacitadas de acordo com o local, para a melhor acomodação do cliente. A aparência e o comportamento são aspectos que influenciam. É importante que vivam a cultura da empresa e conheçam a fundo cada produto oferecido, assim como o seu processo de fabricação e história da marca (D’ANGELO, 2004). Existem pessoas que julgam as outras de acordo com sua vestimenta, o pré-conceito no atendimento é o item que será discutido na próxima seção.

\subsection{Pré-Conceito no Atendimento e Formação de Estereótipos}

O pré-conceito é uma atitude de desrespeito a outras pessoas em qualquer tipo de relação, seja ela cometida contra um grupo inteiro ou contra indivíduos que pertençam a ele, é uma função irracional (JAHODA, et al.,1969). Em um mundo tão moderno como a realidade de hoje, dizem que o pré-conceito está diminuindo, mais isso é tão contraditório como o próprio indivíduo observador, que se considera culto, justo e liberalista, e ao mesmo tendo se abstém de dividir seu espaço com aqueles que se descaracterizam como pertencentes de seu grupo social (ALMEIDA, 2009).

Alguns acontecimentos de preconceito em diversos tipos de lugares provocam uma criação de estereótipos em relação aos clientes. Estereótipos, segundo Oakes, Haslam e Turner (1994), é definido como o processo de julgar as pessoas e atribui-las características de acordo com pessoas que ela convive, é um processo de atribuir característica a uma pessoa de acordo com sua aparência, sem saber quem realmente é a pessoa.

Ao se deparar, por exemplo, com meninos de rua lanchando em um shopping center, algumas pessoas ficariam impactadas devido sua aversão, seus pré-conceitos sociais, sua moral e sua boa educação. Determinados indivíduos não sabem se comportar em uma situação como essa e acabam deixando o recinto ou simplesmente ignoram o fato. Muitos consumidores, ao deparar-se com clientes malvestidos, por pré-conceitos, deixam o ambiente enojados e procuram por lugares onde não há clientes assim (ALMEIDA, 2009).

Segundo Elias e Scotson (2000), a existência do pré-conceito e da estereotipação, ocorre porque a maioria das pessoas estabelecem certos valores e características consideradas 
negativas para uma minoria de pessoas com o objetivo de desconsiderá-las da sociedade. Para Almeida (2009), um fato como esse não desafia apenas o senso comum, a moral e a ética, como também o senso de justiça e os pré-conceitos que cada pessoa, seja cliente da lanchonete ou mesmo uma pessoa que estivesse passando por ali. Vem sendo disseminado na sociedade o pré-conceito com aqueles menos desfavorecidos, transparecendo que aquele lugar não é adequado para determinado tipo de público, contradizendo o discurso de pessoas que se consideram justas e liberalistas.

A existência do pré-conceito e da estereotipação ocorre porque a maioria das pessoas estabelecem certos valores e características consideradas negativas para uma minoria de pessoas com o objetivo de isolá-las da sociedade (ELIAS; SCOTSON, 2000). De acordo com Riggio, Widaman, Tucker, Salinas (1991), um funcionário com uma boa simpatia facial e uma boa expressividade são as principais contribuições para atrair novos clientes, já que o preconceito e a estereotipação são fatos comuns em várias empresas de diversos setores, e para os clientes se sentirem bem em um determinado lugar é necessário melhor a qualidade da empresa, treinando os funcionários, para diminuir o pré-conceito com qualquer cliente.

\section{METODOLOGIA}

Quanto aos objetivos, o presente trabalho caracteriza-se como descritivo. A pesquisa descritiva objetiva conhecer e interpretar a realidade sem modificá-la ou nela interferir (CHURCHILL, 1987). O interesse da pesquisa está em descobrir e observar os fenômenos, procurando interpretá-los, classificá-los e descrevê-los.

Quanto a abordagem, considera-se que o estudo em questão é do tipo qualitativa. De acordo com Malhotra (2010), a pesquisa qualitativa apresenta alguns procedimentos de pesquisa que são classificados como diretos e indiretos, dependendo se o entrevistado conhece ou não o objetivo do projeto desenvolvido. Quando a abordagem é direta, ela é revelada aos entrevistados ou então fica evidente nas questões formuladas.

Para contemplar a abordagem qualitativa, dois clientes espiões, sendo um do gênero feminino e outro do gênero masculino, visitaram seis lojas de varejo de luxo numa cidade no interior de Minas Gerais, de um total de 22 lojas identificadas pela lista telefônica, seis vendem roupas de grifes, onde metade das lojas avaliadas (três) é voltada para o público feminino e a outra metade para o público masculino. As lojas foram nomeadas em Loja A, B, 
C, D, E e F, para resguardar os nomes originais. A cliente espiã do gênero feminino visitou as três lojas femininas e o cliente espião masculino visitou as três lojas masculinas.

Os clientes espiões foram ora bem vestidos, usando roupas formais, ora usando vestimentas comuns e de certa forma, compostos pelo estereótipo de malvestidos. O processo foi executado da seguinte forma: em uma semana, os clientes espiões visitaram as lojas malvestidos e fizeram seus relatos após o atendimento. Uma semana mais tarde, visitaram as mesmas lojas bem vestidos e refizeram seus relatos, para verificar se há discrepância no atendimento em função da vestimenta utilizada. Os clientes espiões procuraram o mesmo vendedor que os atenderam anteriormente e no decorrer do atendimento, o cliente espião fez observações sobre a forma como foi atendido em virtude da forma como estava vestido.

Os dados qualitativos foram analisados usando-se a técnica análise de conteúdo. Segundo Bardin (1977, p. 42), a análise de conteúdo pode ser entendida como um conjunto de técnicas de análise das comunicações visando obter, por procedimentos sistemáticos e objetivos de descrição do conteúdo das mensagens, indicadores (quantitativos ou não) que permitam a inferência de conhecimentos relativos às condições de produção/recepção (variáveis inferidas) destas mensagens.

\section{RESULTADOS E ANÁLISE}

O objetivo desta pesquisa foi identificar se há preconceito no atendimento das lojas de confecções de luxo em função da vestimenta usada pelos clientes. Visando alcançar o objetivo proposto, utilizou-se como coleta de dados a técnica do cliente espião.

Para as visitas as lojas, a pesquisa foi dividida em duas etapas, usando dois clientes espiões, um do gênero feminino e outro do gênero masculino. No primeiro momento, ambos os clientes espiões foram às lojas malvestidos, usando roupas mais velhas, com propagandas e sem nenhum tipo de maquiagem ou acessório, calçando chinelos e sandálias velhas. Em um segundo momento, depois de uma semana, voltaram às mesmas lojas bem vestidos, usando roupas novas e da moda, calçados novos, acessórios que combinavam com as roupas e maquiagem leve.

Foi realizada a mesma simulação de compra nas duas visitas, pedindo para ver os produtos que a loja oferecia, onde foram analisados todos os passos do atendimento, que se dividiram em quatro partes: entrada na loja, abordagem do funcionário, qualidade do atendimento e saída da loja. 
$\mathrm{Na}$ entrada da loja, o cliente espião observou a reação dos funcionários e a forma como os outros clientes que estavam na loja o olharam. Já na abordagem do funcionário, verificou-se se o atendente o tratou com simpatia ou indiferença e a forma como conversou questionando qual produto o cliente desejava olhar. Segundo Greis e Silva (2001), as estratégias apontam para a qualidade do atendimento aos clientes, tornando-se a dever das empresas oferecer um atendimento diferenciado, que chame a atenção do cliente. Logo, foi observada a prestação de serviço ao cliente, além da disposição em atender e mostrar os produtos da loja e, por fim, a saída da loja, na qual quando o cliente falou que não era aquele produto que procurava, sendo analisada a reação do vendedor: se simplesmente deixou o cliente ir embora ou se ofereceu outros produtos.

Em todas as etapas foram analisadas a reação do funcionário quando o cliente entrou na loja, a disposição em mostrar os produtos, a simpatia no decorrer do atendimento e como o funcionário se comportou quando o cliente espião decidiu não levar o produto, fatores estes que colaboram para a satisfação do cliente. Para Schiffman e Kanuk (2009) a satisfação do cliente é a percepção individual do desempenho do produto ou serviço em relação a suas expectativas. $\mathrm{O}$ conceito de satisfação do cliente é construído em função de suas expectativas.

Os resultados da pesquisa estão divididos em dois quadros, onde o primeiro contém uma comparação do atendimento ao cliente espiã do gênero feminino (quadro 1), mostrando os principais pontos nas duas etapas das visitas às lojas, enquanto que no segundo quadro, os mesmos pontos são analisados, porém em relação ao cliente espião masculino (quadro 2).

Quadro 01 - Síntese da cliente espiã nas três lojas do varejo de luxo visitadas

\begin{tabular}{|c|l|l|}
\hline Loja & $\begin{array}{l}\text { Malvestida - camiseta branca propaganda } \\
\text { (doação de sangue) cortada, short jeans desfiado e } \\
\text { rasteirinha. }\end{array}$ & $\begin{array}{l}\text { Bem vestida - saia curta (estampas da moda) de } \\
\text { babados, blusa branca com detalhes de renda, sapato } \\
\text { fechado de bico fino amarelo, cabelos bem arrumados } \\
\text { e com boa aparência e maquiagem leve. }\end{array}$ \\
\hline $\mathbf{A}$ & $\begin{array}{l}\text { Um atendimento rápido, a cliente estava em busca } \\
\text { de uma blusa, a vendedora apenas mostrou o local } \\
\text { onde estavam e foi fazer outras coisas. Tratou a } \\
\text { cliente com desprezo. }\end{array}$ & $\begin{array}{l}\text { O atendimento foi mais demorado. A vendedora se } \\
\text { preocupou com a cliente, com a numeração da roupa e } \\
\text { opções que ela gostaria. Enquanto a cliente } \\
\text { experimentava as blusas, a vendedora trouxe outras } \\
\text { opções de shorts e saias. Foi um atendimento } \\
\text { simpático e prestativo. }\end{array}$ \\
\hline $\mathbf{B}$ & $\begin{array}{l}\text { Atendimento rápido e com desprezo. A vendedora } \\
\text { não se mostrou interessada em vender para a } \\
\text { cliente, mostrou apenas o que ela pediu e quando } \\
\text { a cliente falou que não era aquilo o que } \\
\text { procurava, já se despediu de forma grossa. }\end{array}$ & $\begin{array}{l}\text { Um atendimento simpático, onde a vendedora estava } \\
\text { disposta a oferecer o melhor para a cliente, além das } \\
\text { sandálias que a cliente procurava, ofereceu roupas da } \\
\text { loja que combinassem para ela experimentar. Foi um } \\
\text { serviço de boa qualidade, persistiu na venda de } \\
\text { alguma mercadoria e em outras formas de negociação } \\
\text { e por fim, entregou um cartão da loja para futuras } \\
\text { compras. }\end{array}$ \\
\hline
\end{tabular}


C produro que a cliente escolheu vã ting numeração, então a vendedora, de forma educada, mostrou outras opções, porém, com um preço mais baixo, julgando-se acessível de acordo com as vestimentas da cliente.

Um atendimento discreto, notaram-se olhares de desprezo por parte dos outros clientes que $\mathrm{O}$ atendimento foi de forma prestativa; a vendedora estavam na loja e das outras vendedoras. O procurou deixar a cliente bem à vontade, mostrou várias opções de acordo com sua numeração, foi atenciosa e mesmo quando a cliente disse que não iria levar nenhuma mercadoria, a vendedora foi educada e compreensiva.

Fonte: Dados da pesquisa (2014)

$\mathrm{Na}$ Loja A, quando a cliente estava malvestida, observou-se o preconceito por parte da vendedora, logo no início da compra. Quando a cliente entrou na loja foi uma abordagem comum, sem nenhum tipo de simpatia ao recepciona-la, fato que foi relatado na seguinte fala: “já me recepcionou com um clássico 'posso ajudar?', também não disse nem um mero bom dia, falei que queria olhar algumas camisas e ela me mostrou uma arara e disse que as camisas que ela tinha estavam todas ali."

Percebe-se que quando as pessoas estão usando vestimentas simples, os funcionários não se importam muito, deixam o cliente olhando as roupas e vão realizar outras atividades, sem estar ali ajudando com um atendimento de boa qualidade, fato que a cliente destacou pelo seguinte acontecimento: "depois de responder sobre a forma de pagamento, ela se afastou para atender ao telefone e não voltou mais. Então eu disse de longe para ela que ia dar mais uma olhada e qualquer coisa eu voltava depois, ela disse 'tá' e ficou por isso mesmo. " Nessa etapa, em relação à qualidade do atendimento, nota-se que a vendedora não se interessou em ajudar a cliente, mostrar os produtos da loja, os itens que combinariam com o que a cliente procurava, foi realizar outra atividade e não se preocupou com a cliente, deixando-a ir embora sem adquirir nenhum produto, fato que baseado no referencial teórico se contradiz a maneira como deve ser realizado o atendimento, pois segundo Martins (1998), o cliente se tornava uma pessoa mais exigente, que além de um produto de qualidade, queria algo diferente, buscando também a inovação. Ele é único e quer ser tratado como tal.

$\mathrm{Na}$ mesma loja, quando a cliente espiã mudou sua vestimenta, notou-se uma simpatia por parte da funcionária, no momento em que a cliente entrou na loja, houve a preocupação com a qualidade do atendimento, a vendedora estava disposta a vender algum produto, procurando deixar a cliente satisfeita e oferecendo outros itens além do que a cliente buscava, o que foi relatado na seguinte fala: "entrei no provador e enquanto eu experimentava as camisas ela me trouxe opções de shorts e calças que combinariam com as camisas. Ao sair do provador, ela perguntou o que eu tinha achado das peças, eu respondi que tinha gostado, mas que ainda estava em dúvida”. Mesmo a cliente não comprando nenhum produto, a vendedora 
foi simpática durante todo o atendimento e educada, respeitando a opção da cliente de ir embora sem comprar nada, como citado no referencial teórico, o termo qualidade significa satisfazer o consumidor atendendo todas as suas necessidades.

Diante dos fatos analisados, constata-se claramente que houve discriminação por parte da vendedora em relação às vestimentas da cliente e que, quando ela foi vestida da forma julgada adequada, a vontade de vender o produto foi maior.

$\mathrm{Na}$ Loja $\mathrm{B}$, o fato do preconceito se repete, porém, de forma mais nítida e maleducada. Logo no início, quando a cliente entrou na loja houve uma rejeição por parte de duas vendedoras que ficaram observando a cliente para ver se ela realmente estava interessada em comprar, acontecimento que se passa na seguinte fala: "ao entrar na loja, fiquei esperando alguns instantes por uma atendente (tinham duas no balcão e elas viram a hora que eu entrei), fiquei esperando alguém vir atender, próxima à prateleira de sapatos, aí quando uma delas veio até a minha pessoa foi direta e seca no 'posso ajudar?', não disse nem um mero bom dia, não me olhava diretamente e sempre estava olhando pra outro lugar." Esse fato é comum em abordagens de vendedores quando uma pessoa vestida com roupas mais simples ao entrar em um local em que as vendedoras julgam inadequadas. As vendedoras têm a opinião de que se a pessoa está malvestida não irá comprar nenhum produto, pois não tem condições. O cliente já sabe o que procura dependendo da forma como é atendido, e transmite a outras pessoas, segundo Martins (1998), o cliente não está mais em busca de opções, ele sabe exatamente o que quer ou, pelo menos, sabe o que não quer. Atendimento de baixa qualidade, displicência e desinteresse são atitudes que desencantam o cliente e ele desaparece. Muito provavelmente, levando outros juntos. Notou-se um atendimento rápido, a vendedora não tinha simpatia, a realização ou não da compra não mudaria nada para ela. Por fim, quando a cliente decidiu não levar os produtos, a vendedora foi breve em suas palavras, fato relatado na seguinte fala: "depois de responder sobre a forma de pagamento, ela ficou calada, aí falei que não ia levar porque tinha ficado apertado; ela não insistiu, perguntou se eu queria dar uma olhada em mais alguma coisa aí eu disse que não, ela soltou um belo então 'tá' e tchau. " Nesse fato, a vendedora não insistiu na compra e nem com a presença da cliente na loja, a partir daquele momento. Já quando a cliente espiã estava bem vestida, as mudanças foram bem visíveis. Quando a cliente entrou na loja, foi abordada de uma forma educada por parte da vendedora, conforme relato na seguinte fala: "ao entrar na loja já dei de cara com um atendente simpaticíssima, que perguntou se podia me ajudar. " A vendedora foi persistente, mostrou 
várias formas de pagamento, concedeu descontos e mostrou outras peças da loja, além das solicitadas pela cliente, oferecendo um atendimento de boa qualidade que foi relatado na seguinte fala: "das três sandálias que eu demonstrei interesse e tinha experimentado disse que eu tinha ficado em dúvida entre duas, perguntei então o preço das sandálias e ela respondeu ( $\mathrm{R} \$ 195,90$ e $\mathrm{R} \$ 235,00)$ e as formas de pagamento. Depois de responder sobre a forma de pagamento, eu disse que a sandália ainda não era aquilo que eu estava buscando; ela rapidamente disse que as duas tinham ficado muito bonitas no meu pé e que se eu quisesse levar as duas ela podia fazer uma negociação mais interessante. " Percebe-se a disposição em atender a cliente, procurando deixá-la bem à vontade quanto às formas de pagamento, e, por fim, quando a cliente disse que não iria comprar nenhum produto, a vendedora continuou sendo simpática até a cliente se retirar na loja, procurando formas de deixar nítido que a loja estava à disposição, caso ela resolvesse comprar algum produto, somente pelo fato da cliente estar bem vestida, fato que foi observado na seguinte fala: "eu continuei afirmando que iria dar mais uma olhada, ela perguntou então se eu não tinha gostado do vestido ou do short que ela tinha me oferecido para experimentar com as sandálias disse que sim, mas que naquele momento estava procurando mesmo era uma sandália. A vendedora então me entregou um cartão da loja com o nome dela e disse que se eu mudasse de ideia era para procurar ela, e então eu agradeci e saí da loja."

A qualidade do atendimento sofreu uma variação pelo fato das vestimentas, a simpatia em atender a cliente existiu apenas na segunda visita, onde deixou as portas abertas para futuras compras na loja, conforme foi estudado no referencial teórico, esses acontecimentos de preconceito em diversos tipos de lugares provocam uma estereotipação em relação aos clientes, onde o conceito de estereótipos segundo Oakes, Haslam, e Turner (1994) é definido como o processo de julgar as pessoas e atribui-las características de acordo com pessoas que ela convive, é um processo de atribuir característica a uma pessoa de acordo com sua aparência, sem saber quem realmente é a pessoa.

Na última loja visitada pela cliente espiã, a loja $\mathrm{C}$, existiu um aspecto não notado nas outras lojas visitadas, o preconceito ocorreu também por parte dos demais clientes presentes na loja, que deixaram de realizar sua compra e olharam com pouco caso, quando a cliente entrou na loja com as vestimentas mais simples. Quando a vendedora realizou o atendimento, foi educada, tratando-a de forma normal como as demais clientes, porém mostrando sapatos com preços mais baixos, mas sem constranger a cliente, jugando-se acessível às vestimentas 
da cliente, relato que se encontra na seguinte fala: "quando cheguei notei olhares voltados para mim, tanto das vendedoras quanto dos outros clientes. A vendedora que me atendeu, teve pelo menos a delicadeza de me atender, mostrar os produtos e de uma maneira discreta me mostrar algo que ela julgava caber no meu orçamento." Com esse fato, observa-se que além dos funcionários, as outras pessoas que frequentam a loja, também analisam os demais clientes, tem a preocupação de que se aquele local que estão frequentando está no patamar alto. No final do atendimento, a vendedora de forma educada agradeceu, sem insistir em mostrar outros produtos. Quando a cliente espiã voltou à loja com vestimentas mais adequadas ao estilo da loja, o atendimento foi melhor do que anterior, iniciando com uma boa abordagem quando entrou na loja, como foi relatado na seguinte fala: "ao entrar na loja veio em minha direção uma atendente, que de cara já me disse um bom dia e abriu um belo sorriso, perguntou se podia me ajudar. "Durante o atendimento, procurou deixar a cliente mais confortável na hora de realizar a compra, como demostra a seguinte fala: "falei que estava à procura de uma sandália de salto alto confortável, então ela me perguntou quais seriam as minhas preferencias de cores e qual era a minha numeração, respondi e logo ela trouxe cinco pares para que eu pudesse experimentar, enquanto eu experimentava ela perguntou se eu aceitava água. " Assim como nas outras lojas, a cliente disse que não era aquilo que buscava, então logo a vendedora já queria oferecer outras opções, mas como não houve efetivação da compra, ela foi educada e agradeceu pelo atendimento. Nesse caso, observou-se a preocupação por parte da atendente não só com os produtos, mas com o bem-estar da cliente, que ele se sentisse bem no ambiente da loja, como mostra no referencial teórico, os serviços são considerados intangíveis. Por isso, em muitos casos, os consumidores avaliam a qualidade de uma empresa na sua imagem, no ambiente em que é oferecido um serviço, e com isso as empresas trabalham sua imagem, voltada para a satisfação do consumidor (LOVELOCK; WIRTZ; HEMZO, 2011).

O tratamento com a cliente espiã foi educado, no primeiro momento não existiu preconceito, foi uma abordagem em que foram mostrados produtos que a vendedora julgou estar no orçamento da cliente, nas condições em que ela poderia pagar. Realizando uma análise mais profunda, nota-se que quando a vendedora mostra produtos mais baratos, mesmo de forma discreta já é o início de um preconceito, pois julga as vestimentas da cliente.

Quadro 02 - Síntese do cliente espião nas três lojas do varejo de luxo visitadas 


\begin{tabular}{|c|l|l|}
\hline Loja & $\begin{array}{l}\text { Malvestido - Camisa lisa mais velha, short e } \\
\text { chinelos, com uma mochila nas costas. }\end{array}$ & $\begin{array}{l}\text { Bem vestido - Camiseta com estampa, calça jeans } \\
\text { clara e macboot (botinha) }\end{array}$ \\
\hline D & $\begin{array}{l}\text { Atendimento rápido, o cliente estava em busca } \\
\text { de uma camisa para uma formatura, a a } \\
\text { vendedora quando viu sua vestimenta, focou } \\
\text { em mostrar camisetas que estavam na } \\
\text { promoção. }\end{array}$ & $\begin{array}{l}\text { Como o cliente já estava bem vestido, a vendedora } \\
\text { mostrou várias opções de camisa, de acordo com o } \\
\text { cliente, foram muitas peças expostas, a vendedora } \\
\text { insistiu em uma venda. }\end{array}$ \\
\hline E & $\begin{array}{l}\text { Não notou se desprezo pela vestimenta, } \\
\text { mostrou os produtos, mas a vendedora focou } \\
\text { nas formas de pagamento dos produtos. }\end{array}$ & $\begin{array}{l}\text { A vendedora não falou em formas de pagamento, o } \\
\text { atendimento foi mais simpático. }\end{array}$ \\
\hline F & $\begin{array}{l}\text { Atendimento normal, mostrando os produtos } \\
\text { solicitados pelo cliente, falando do preço e das } \\
\text { formas de pagamento. }\end{array}$ & $\begin{array}{l}\text { Não citou formas de pagamento, mostrou mais } \\
\text { produtos, procurando satisfazer a necessidade do } \\
\text { cliente, o que ele estava em busca. }\end{array}$ \\
\hline
\end{tabular}

Fonte: Dados da pesquisa (2014).

Realizando a análise do cliente espião do gênero masculino, a diferença nos atendimentos é menor do que os fatos acontecidos com a cliente espiã do gênero feminino. A técnica de pesquisa realizada foi a mesma: o cliente espião realizou visitas em três lojas distintas de varejo de luxo. No primeiro momento, usava vestimentas simples, camisa lisa mais velha, short e chinelos, com uma mochila nas costas. No segundo momento, usava roupas mais sofisticadas, camiseta com estampa, calça jeans clara e macboot (botinha).

Houve uma semelhança no atendimento nas três lojas, no momento em que o cliente espião, usava vestimenta simples, todas foram receptivas, realizaram um atendimento normal, de acordo com o padrão, conforme relatado pelo cliente na seguinte fala: "todos me atenderam normalmente, não notei nenhum tipo de discriminação ao olharem minha aparência. "Mas julgando suas roupas procuravam mostrar produtos mais baratos da promoção e falavam o tempo todo em forma de pagamento, fato que é relatado na seguinte fala: “Eu estava em busca de uma camisa para formatura, que era mais cara, porém a vendedora só me mostrava as peças que estavam na promoção, falando que eram boas e mais baratas." , onde observa-se uma das características das lojas de varejo, que para Schiffman e Kanuk (2009) as lojas de varejo tem suas próprias imagens que servem para influenciar a qualidade percebida dos produtos de que dispõem e as decisões dos consumidores sobre onde comprar.

Já no momento em que o cliente estava bem vestido, os atendimentos nas três lojas foram distintos quanto a forma de demonstração dos produtos. Ao entrar nas três lojas, o cliente espião foi bem recebido e houve uma abordagem simpática por parte das vendedoras, conforme relato na seguinte fala: "quando entrei nas três lojas, as vendedoras me receberam bem-educadas e simpáticas." O atendimento na loja $\mathrm{D}$, foi de boa qualidade, a vendedora 
estava empenhada a fazer com que o cliente comprasse um produto, mostrou várias opções sem citar preços e formas de pagamentos, o que é notado na seguinte fala: "a vendedora não falou em preços, trouxe muitas peças, eu já estava sem graça com tantas camisas que ela me mostrou. " Ao final, quando o cliente decidiu por não comprar nenhuma peça, a vendedora de forma educada mostrou mais peças com o propósito de agradar o cliente e levá-lo a comprar alguma camisa, e quando não comprou nenhuma mercadoria, a vendedora agradeceu e foi simpática. Onde se percebe uma das questões relevantes no varejo de luxo é a qualidade no atendimento prestado. De acordo com Faria (2012), é no varejo que ocorre a união de fatores racionais e emocionais que levam o consumidor à decisão final de compra.

Já na loja E, o atendimento foi objetivo, porém simpático. A vendedora mostrou algumas peças, e não houve insistência para a compra e nem mostrou mais opções, de acordo com o cliente espião na seguinte fala: "o atendimento foi rápido, de forma objetiva, a vendedora me mostrou algumas peças e citou preços." Como o cliente não realizou a compra, a vendedora não insistiu e o cliente foi embora sem restrições, como citado no referencial teórico, segundo Matos (2000), a velocidade de atendimento demonstra a prontidão da organização e de seus atendentes na prestação do serviço.

Por fim, na loja F, o atendimento foi destacado pela gentileza, a vendedora procurava deixar o cliente bem à vontade quando ele olhava os produtos, fato que é relatado na seguinte fala: "a vendedora procurava de todas as formas me deixar à vontade na loja, mostrando várias opções de camisa para o meu perfil." E como nas outras lojas, essa também citou formas de pagamento; a preocupação foi em atender bem o cliente e mostrar os diversos produtos da loja. Mesmo no momento em que o cliente decidiu por não adquirir nenhum produto, a vendedora foi gentil e agradeceu, onde foi constatado que a loja se preocupa com o cliente e de acordo com Schiffman e Kanuk (2009), citado no referencial teórico, a satisfação do cliente é a percepção individual do desempenho do produto ou serviço em relação a suas expectativas. O conceito de satisfação do cliente decorre em função de suas expectativas.

\section{CONCLUSÃO}

O objetivo do trabalho foi a identificação acerca da presença de preconceito no atendimento das lojas de confecções de luxo em função da vestimenta usada pelos clientes, verificando se a forma como os clientes estão vestidos interfere na qualidade do atendimento prestado pelos vendedores, analisando aspectos como o comportamento do vendedor desde o 
momento que o cliente entra na loja, a prestação de serviços durante o atendimento, até o momento em que ele deixa a loja.

Foi possível constatar que existe o preconceito por parte dos vendedores em relação às vestimentas usadas pelos clientes e que esse preconceito apresenta maior evidência nas mulheres. A análise da cliente espiã apresenta resultados semelhantes e que são destacados como: 1) as vendedoras receberam a cliente demonstrando nenhuma vontade em atendê-la, no momento em que ela estava malvestida; 2) em todas as lojas, foi mostrado apenas o que a cliente estava buscando; 3) não houve insistência para a cliente levar um produto da loja; 4) foi um atendimento rápido e objetivo; e no momento em que a cliente espiã voltou as lojas bem vestida, destacam-se fatos como: 1) ao entrar nas lojas, a cliente foi bem recebida em todas; 2) as vendedoras mostraram outros produtos além do que a cliente buscava; 3) a cliente foi bem atendida, e houve insistência por parte das vendedoras para comprar algum produto, apresentando outras formas de negociação; 4) as vendedoras foram educadas e simpáticas, procurando deixar a cliente à vontade.

Já no atendimento com o cliente espião do gênero masculino, as evidências foram que em todas as lojas, no momento em que ele estava malvestido, as vendedoras citavam preços e formas de pagamento, mostrando apenas o que ele busca, e quando ele voltou às lojas bem vestido não foi citado formas de pagamento e as vendedoras mostraram muitas opções de produtos, além do que ele procurava.

Verificou-se, portanto, que as mulheres sofrem mais com o preconceito em lojas do varejo de luxo, e que a forma como elas estão vestidas, ou seja, a imagem que elas transmitem, influencia na qualidade do atendimento. Ao entrar numa loja para a realização de uma compra, são julgadas pela forma como estão vestidas, provocam reações nas vendedoras de realizar o atendimento por obrigação. Confirmou-se ainda que se tratando de clientes do gênero masculino, o preconceito está relacionado ao preço dos produtos e às formas de pagamento, itens que foram destacados no atendimento em que o cliente espião estava malvestido.

Em ambos os casos, percebe-se que a forma de vestimenta interfere na qualidade do atendimento, sendo notado que a demonstração dos produtos para os clientes enquanto malvestidos é menor do que enquanto bem vestidos.

O trabalho possui limitações, uma vez que a pesquisa foi realizada com o intervalo de tempo de uma semana, podendo fazer com que a vendedora se lembrasse do cliente e por não 
ter adquirido nenhum produto na primeira visita, o atendimento foi melhor na segunda visita, pois além de estar bem vestido, o cliente voltou à loja.

A pesquisa foi realizada com jovens de 19 e 22 anos, podendo impactar de que não iriam comprar, apenas estavam olhando o produto e que por serem jovens não teriam condições de estar pagando pelo preço, enquanto malvestidos.

Por fim, mesmo a pesquisa sendo feita em um intervalo curto de tempo e os clientes espiões serem jovens, obteve-se um resultado satisfatório, onde foi possível ver, nitidamente, o preconceito com pessoas malvestidas e para obtenção de resultados diferentes.

Sugere-se para futuros estudos que a pesquisa seja feita com clientes com tatuagens e, também, que seja feita de forma mais ampla, contemplando outras lojas de varejo de luxo e também, outras localidades.

\section{REFERÊNCIAS BIBLIOGRÁFICAS}

ALLPORT. Atitude, Preconceito e Estereótipo. 1954. Disponível em:

$<$ http://www.brasilescola.com/psicologia/atitude-preconceito-estereotipo.htm>. Acesso: 10 abr. 2013.

CASTARÈDE, J. O Luxo. Tradução: Mário Vilela. São Paulo: Barcarolla, 2005.

D'ANGELO, A. C. Precisar, não precisa: um olhar sobre o consumo de luxo no Brasil. São Paulo: Lazuli, 2006. 191 p.

ELIAS, N.; SCOTSON, J.L. Os estabelecidos e os outsiders: sociologia das relações de poder a partir de uma pequena comunidade. Tradução Vera Ribeiro. Rio de Janeiro: Jorge Zahar, 2000.

FARIA, H. F. S. A. O planejamento de comunicação para o varejo de luxo: um planejamento de comunicação para a Sara Boo. 2013. Disponível em: < http://bdm.unb.br/handle/10483/4358 >. Acesso: 07 fev. 2014.

GIANESI, I. F. N.; CORRÊA, H. L. Administração estratégica de serviços: Operações para a satisfação do cliente. 6.ed. São Paulo: Atlas, 1996.

GREIS, I. M. C.; DA SILVA, L. M. R.; DA SILVA, T. J. QUALIDADE NO

ATENDIMENTO NO COMÉRCIO DE GUÍBA. em:

$<$ http://guaiba.ulbra.br/seminario/eventos/2008/artigos/administracao/429.pdf>. Acesso: 31 jan. 2013.

JAHODA, M.; ACKERMAN, N.M. Distúrbios emocionais e anti-semitismo. São Paulo: Perspectiva, 1969.

KOTLER, P.; KELLER, K. L. Administração de Marketing. São Paulo: Pearson, 2006. 
KOTLER, P; KELLER, K. L. (2008). Administração de Marketing: A Bíblia do Marketing. 13. ed. São Paulo: Prentice Hall Brasil.

LOVELOCK, C.; WIRTZ, J. e HEMZON, M. A. Marketing de Serviços. São Paulo: Pearson, 2011.

MALHOTRA N. Pesquisa de Marketing. Porto Alegre: Bookman, 2012.

MARTINS. Qualidade no atendimento. Disponível em:

<http://www.abepro.org.br/biblioteca/ENEGEP1998_ART434.pdf>. Acesso: 02 mar. 2013.

MILAN, G. S. A prática do marketing de relacionamento e a retenção de clientes: um estudo aplicado em um ambiente de serviços. 2006. Disponível em: < http://hdl.handle.net/10183/6463 >. Acesso: 11 jan. 2014.

MILAN, G.S.; TREZ, G. Pesquisa de satisfação: um modelo para planos de saúde. RAE eletrônica, v. 4, n. 2, 2005. Disponível em:

<http://www.scielo.br/pdf/raeel/v4n2/v4n2a02.pdf>. Acesso: 25 jan. 2014.

OAKES, P. J.; HASLAM, S. A.; TURNER, J. C. Stereotyping and social reality. Blackwell Publishing, 1994.

PARENTE, J. Varejo no Brasil: Gestão e estratégia. São Paulo: Atlas, 2000.

RAPP, S. \& COLLINS, T. L. O Novo Maximarketing: O Guia Clássico para Adequar sua Estratégia de Propaganda, Promoção e Marketing na Economia da Informação. São Paulo. Makron Books, 1996.

RIGGIO, R.E.;WIDAMAN, K.F.; TUCKER, J.S.; SALINAS, C. Beauty is more than skin deep: Components of attractiveness. Basic and Applied Social Psychology, 1991.

ROCHA, J. R. V.; LIMA, M. A. M.; ROCHA, R. E. V. QUALIDADE DE ATENDIMENTO NA AUTARQUIA MUNICIPAL DE TRÂNSITO, SERVIÇOS PÚBLICOS E DE CIDADANIA DE FORTALEZA (AMC). ANÁLISE À LUZ DO MODELO SERVQUAL.

REVISTA DA FA7, v. 1, n. 7, p. 91, 2009.. (2009). Disponível em:

$<$ http://parati.fa7.edu.br/recursos/imagens/File/Revista\%20FA7/revista2009_1.pdf\#page=91 >Acesso: 13 jan. 2014.

SCHIFFMAN, L. G.; KANUK, L. L. Comportamento do consumidor. Rio de Janeiro: Ltc, 2009.

SOARES, S.S.D. Perfil da discriminação no mercado de trabalho: homens negros, mulheres brancas e mulheres negras. 2000. Disponível em:

<http://www.aids.gov.br/sites/default/files/anexos_campanhas/2010/42631/trabalho.pdf>. Acesso: 05 fev. 2014. 
SANTOS E GOMES. Dimensões do ambiente varejista sob a perspectiva dos consumidores: um estudo de caso em lojas de calçados em Vitória da Conquista.

Disponível em:

<http://periodicos.uesb.br/index.php/cadernosdeciencias/article/viewFile/887/894>

Acesso: 01 fev.2014

SHAPIRO, Bensone SVIOKLA, John. Mantendo Clientes. São Paulo: Makron Books,1995.

TEIXEIRA, L. R.; DE FREITAS, Z. B. ATENDIMENTO AO CLIENTE. Cadernos

Temáticos, p. 2, 2004.. Disponível em:

$<$ http://www.unifemm.edu.br/publicacoes/arquivos/Cadernos_Tematicos_4.pdf\#page=2>.

Acesso: 26 jan. 2013.

VIEIRA, M. F.; DEL-VECHIO, R. O consumo de produtos de luxo: Um estudo teórico sobre o mercado da moda. Revista da UNIFEBE, v. 1, n. 09, 2011. Disponível em:

<http://www.unifebe.edu.br/revistadaunifebe/2011/artigo016.pdf>. Acesso: 21 ago. 2013.

XAVIER, R. F. F. Qualidade no atendimento: estudo de caso na loja de confecções kikorum jeans wear em Santa Cruz do Capibaribe-PE. Disponível em:

<http://repositorio.favip.edu.br:8080/bitstream/123456789/1278/1/TCC_RUPIANO_REVISA DO_08062011.pdf>. Acesso: 06 fev. 2013.

ROUX, E. Tempo do luxo, tempo das marcas. In: LIPOVETSKY, Gilles; ROUX, Elyette. O luxo eterno. Tradução: Maria Lúcia Machado. São Paulo: Cia das Letras, 2005.

SCHMID, E. F. Varejo de moda - estratégias de marketing para diferenciação diante da concorrência. In: ANGELO, Cláudio F.; SILVEIRA José A. G. Varejo competitivo. São Paulo: Atlas, p.107-133, 2003. 